\title{
Are Trabecular Metal Cones a Valid Option to Treat Metaphyseal Bone Defects in Complex Primary and Revision Knee Arthroplasty?
}

\author{
Tommaso Bonanzinga ${ }^{1,2,3}$ Thorsten Gehrke ${ }^{4}$ Akos Zahar ${ }^{4}$ Stefano Zaffagnini²,3,5 \\ Maurilio Marcacci ${ }^{1,6}$ Carl Haasper ${ }^{2}$ \\ ${ }^{1}$ Istituto Clinico Humanitas, Rozzano, Milano, Italy \\ ${ }^{2}$ Dipartimento Scienze Biomediche e Neuromotorie, DIBINEM, \\ Università di Bologna, Bologna, Italy \\ ${ }^{3}$ Istituto Ortopedico Rizzoli, Laboratorio di Biomeccanica e \\ Innovazione Tecnologica, Bologna, Italy \\ ${ }^{4}$ HELIOS ENDO Klinik, Hamburg, Germany \\ ${ }^{5}$ Istituto Ortopedico Rizzoli, Clinica Ortopedica e Traumatologica I, \\ Bologna, Italy \\ ${ }^{6}$ Humanitas University, Rozzano, Milano, Italy \\ Address for correspondence Tommaso Bonanzinga, MD, Istituto \\ Clinico Humanitas, Rozzano, Milano 20159, Italy \\ (e-mail: t.bonanzinga@gmail.com).
}

Joints 2018;6:58-64.

\begin{abstract}
Keywords

- metaphyseal

- cones

- tantalum

- knee

- revision

Purpose Metaphyseal bone defects are a challenge in complex primary and revision total knee arthroplasty (TKA). Recently, several studies have been published with promising results about the use of Trabecular Metal (TM) cones to address bone defects. The aim of this study is to review the literature to assess the efficacy of TM cones to address metaphyseal bone loss.

Methods A comprehensive search was performed on PubMed, Medline, CINAHL, Cochrane, Embase, and Google Scholar databases using various combinations of the following keywords: "metaphyseal," "cones," "tantalum," "knee," and "revision." Only papers reporting clinical data about the use of trabecular metal cones were included in the analysis. In vitro studies, case reports, surgical technique, or other studies where it was not possible to collect clinical data were excluded. Patients characteristics, details of the surgical procedures, outcome, and complications were collected from each included study.

Results No controlled studies were available in the literature and all the papers were case series. In 16 studies included, the records of 442 patients with 447 implants and 523 TM cones were reported. The mean follow-up was 42 months (range: $5-105$ ) for 360 procedures. Among 437 procedures, 30.4\% were septic revisions. The Anderson Orthopaedic Research Institute (AORI) classification was available for 352 defects: 13 type 1, 69 type 2A, 115 type $2 \mathrm{~B}$, and 155 type 3 . To manage these 352 defects, $360 \mathrm{TM}$ cones were implanted. Intraoperative fractures occurred 13 times ( 10 femoral/ 3 tibial), 6 required surgical fixation. The overall infection rate was $7.38 \%$, and the infection rate for the aseptic procedures was $0.99 \%$. An aseptic exchange was performed 13 times, among these procedures two TM cones were loose. Signs of loosening were found just in $1.3 \%$ of the 523 TM cones implanted ( 5 femoral/2 tibial) during 447 procedures.
\end{abstract}

received

June 27, 2017

accepted after revision

October 29, 2017

published online

December 14, 2017
DOI https://doi.org/

10.1055/s-0037-1608950.

ISSN 2282-4324.
Copyright $\odot 2018$ Georg Thieme Verlag License terms

KG Stuttgart · New York (c) $(1) \$$ 
Conclusion The TM cones are an effective solution to manage bone defects in complex primary and revision TKA at intermediate follow-up. The incidence of complications was low; however, the femoral metaphysis proved to be more susceptible to complications.

Level of Evidence Level IV, systematic review of level IV studies.

\section{Introduction}

Significant bone defect can be a challenging clinical problem in revision total knee arthroplasty (TKA) or in certain complex primary cases. Several factors such as stress-shielding, osteolysis, instability, previous implant removal, and/or infection may lead to bone loss. ${ }^{1}$ As described by Morgan-Jones et al, the metaphysis, named "zone 2," is crucial to guarantee axial and rotational stability of an implant. ${ }^{2}$ Therefore, the achievement of a stable fixation at the metaphysis is a key issue for the longevity of the implant as bone deficiency at this level compromises the stability of the whole implant. Metaphyseal bone loss can be classified using the Anderson Orthopaedic Research Institute (AORI) system ${ }^{3}$ (- Table 1). Several surgical strategies are available to address bone loss such as structured bone grafting, metal augment blocks, and tumor implants. ${ }^{4,5}$ Porous tantalum cones have been introduced as an option to restore significant bone defects in revision TKA. ${ }^{6}$

Porous tantalum, commercially known as Trabecular Metal (TM; Zimmer Inc., Warsaw, Indiana, United States), was introduced as appealing coating for cementless implants and bone graft substitute. Characteristically, TM has a high volume porosity ${ }^{7}$ similar to the cancellous bone, low modulus of elasticity, and high coefficient of friction. ${ }^{8}$ Early in vitro studies reported high potential for rapid bony ingrowth within the TM structure. ${ }^{9,10}$ Recently, several studies have been published on this metal augment with interesting results. Therefore, the aim of this article is to review the available literature to evaluate if the TM cones are a valid option to address metaphyseal bone loss in the setting of complex primary and revision TKA.

\section{Methods}

A comprehensive search of PubMed, Medline, CINAHL, Cochrane, Embase, and Google Scholar databases was performed, covering the period between 2004 and 2015. Various combinations of the following keywords were used: "metaphyseal," "cones,"

Table 1 AORI bone defect classification

\begin{tabular}{|l|l|}
\hline Type & Description \\
\hline 1 & Minor defect with intact metaphyseal bone \\
\hline 2 & Defect with damaged metaphyseal bone \\
\hline $2 \mathrm{~A}$ & One femoral or tibial condyle affected \\
\hline $2 \mathrm{~B}$ & Both femoral or tibial condyle affected \\
\hline 3 & $\begin{array}{l}\text { Defect affecting the major portion of } \\
\text { either femoral condyles or tibial plateau }\end{array}$ \\
\hline
\end{tabular}

Abbreviation: AORI, Anderson Orthopaedic Research Institute. “tantalum," “knee," and "revision." Two reviewers have independently examined the titles and abstracts from all identified articles to assess their appropriateness to this research. Fulltext articles were downloaded or purchased when required. In addition, each reference list from the identified articles was manually checked to verify that relevant articles were not missed. A total of 57 articles were obtained. All the studies were in English language. Papers not reporting clinical results about the use of TM cones were excluded. In vitro studies, case reports, or surgical technique papers were excluded as well. Reports on retrieved implants or other studies where it was not possible to collect clinical data of patients that underwent TM cones implantation were excluded.

The quality of reporting of meta-analysis (QUOROM) ${ }^{11}$ flow diagram illustrates the number of studies that have been identified, included, and excluded, along with the reasons for exclusion (-Fig. 1). Further, each study was evaluated in terms of the following variables: level of evidence, ${ }^{12}$ number of patients (females/male), operated knees, patient age (range), follow-up time (range), number of septic revisions, type of implant (revision|primary), level of constraint, type of bone defect according to AORI classification, number of TM cones implanted (tibia/femur), stem fixation technique, type of fixation (cemented/cementless/hybrid), and length of the implanted stems. Complications such as intraoperative fractures (with or without intraoperative fixation) and the incidence of postoperative infections, either recurrent or new infection, were collected as well. Infections occurred after subsequent surgeries were not considered as complications of the replacement procedure involving the TM cones implantation. The included studies were also evaluated in terms of reoperations and the data classified as septic reoperations, including revision and debridement, aseptic revisions, or other surgeries without implant exchange. Among the revision procedures, either septic or aseptic, the status of the involved cones was recorded. Finally, the signs of loosening of the implanted cones, either from radiological evaluation or from surgical reports, were collected.

\section{Statistical Analysis}

Descriptive data collected from selected studies were pooled and expressed as weighted means.

\section{Results}

A total of $16^{13-28}$ studies published from 2006 to 2015 that reported clinical data on the management of metaphyseal bone loss using tantalum cones in the setting of complex primary and revision TKA were included in the systematic review. 


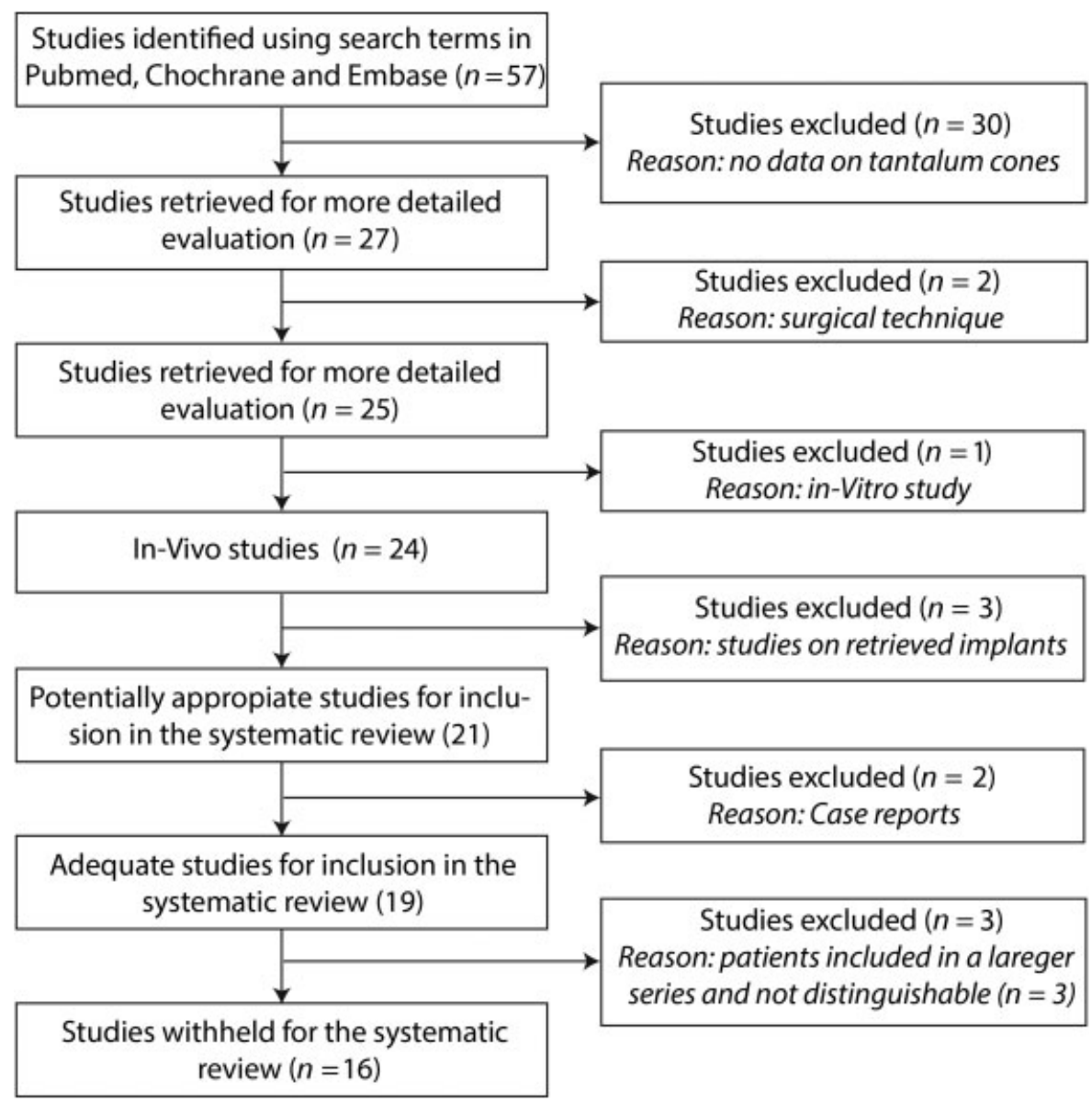

Fig. 1 The quality of reporting of meta-analyses (QUOROM) flow diagram, depicting the number of studies identified, included, and excluded as well as the reasons for exclusion.

\section{Level of Evidence}

No controlled studies were available in the literature. All the papers were case series (Level of Evidence IV).

\section{Patients Demographics}

In 16 studies included, the data of 442 patients with 447 implants were recorded. The gender of the patients and the mean age at surgery was available for 395 patients: 222 females and 173 males, with a mean of 69 years (range: 32-91). In a study including 21 patients, ${ }^{27}$ the follow-up period was not clearly reported. In another paper, ${ }^{28}$ including 66 patients, a different follow-up period for clinical (70 months, range: 60-106) and radiological (68 months, range: 60-106) evaluation was provided. The remaining 358 patients (360 procedures) were evaluated at a mean follow-up of 42 months (range: 5-105). All but one study ${ }^{13}$ specified the number of patients undergoing a septic revision. Therefore, among the 437 procedures described in these studies, $133(30.43 \%)$ were the second stage procedure of a septic revision (-Table $\mathbf{2}$ ).

\section{Surgical Reports}

Out of the 447 replacements included, only 4 were primary procedures. The level of constraint of the implants was clearly specified in 420 cases: 2 implants were cruciate-retaining, 62 posterior-stabilized, 197 constrained condylar, 134 rotating hinge, and 25 pure hinge knees. A detailed AORI classification of the bone defects was provided in 11 studies ${ }^{14,15,17,19,20,24-28}$ including 310 patients presenting with a total of 352 defects (including both femoral and tibial). Thirteen were type 1, 69 type $2 \mathrm{~A}, 115$ type $2 \mathrm{~B}$, and 155 type 3 . In three studies, ${ }^{13,16,21}$ the bone defects classification was not specified; in other two ${ }^{18,23}$ reports, the classification was generally referred to the patients and not to each specific defect. To manage these 352 defects, 360 TM cones were implanted. Overall, 523TM cones, 359 in the tibia and 164 in the femur, were implanted. The stems fixation technique was described for 413 implants including 251 with fully cemented and 162 with hybrid cemented stems. In nine studies, ${ }^{14-18,21-24,28}$ an antibiotic was added to the cement in every procedure, in one ${ }^{20}$ only in selected cases, and in the other five ${ }^{13,16,19,25-27}$ the presence of antibiotic in the cement was not mentioned. The stem length was reported in seven studies ${ }^{13-15,17,19,24,28}$ and it ranged from 30 to $200 \mathrm{~mm}$ (-Table $\mathbf{3}$ ).

\section{Outcomes and Complications}

Intraoperative fractures occurred 13 times (10 in the femur and 3 in the tibia) out of 447 procedures (2.91\%); six (1.34\%) of them required surgical fixation. The overall incidence of septic complications was 33 out of 447 procedures (7.38\%). Of these, 15 cases were described as recurrent infections and 
Table 2 Patients' demographics

\begin{tabular}{|c|c|c|c|c|c|c|}
\hline Author & Year & $\begin{array}{l}\text { Patients } \\
\text { (F|M) }\end{array}$ & Knees & $\begin{array}{l}\text { Age } \\
\text { (range) }\end{array}$ & $\begin{array}{l}\text { Follow-up mo } \\
\text { (range) }\end{array}$ & Septic revisions \\
\hline Radnay and Scuderi & 2006 & 9 (n.s.) & 10 & n.s. & $10(5-14)$ & n.s. \\
\hline Meneghini et al & 2008 & $15(8 \mid 7)$ & 15 & $68(41-81)$ & $34(24-47)$ & 5 \\
\hline Long and Scuderi & 2009 & $15(8 \mid 7)$ & 16 & $66(48-83)$ & $31(24-38)$ & 3 \\
\hline Howard et al & 2011 & $24(13 \mid 11)$ & 24 & $64(46-79)$ & $33(24-50)$ & 7 \\
\hline Lachiewicz et al & 2012 & $27(14 \backslash 13)$ & 27 & $65(49-84)$ & $39(24-68)$ & 13 \\
\hline Schmitz et al & 2013 & 38 (n.s.) & 38 & n.s. & $37(35-42)$ & 0 \\
\hline Rao et al & 2013 & $26(15 \backslash 11)$ & 26 & $72(62-84)$ & $36(24-49)$ & 9 \\
\hline Villanueva-Martínez et al & 2013 & $21(14 \mid 7)$ & 21 & $73(62-86)$ & 36 & 5 \\
\hline Derome et al & 2014 & $29(10 \mid 19)$ & 29 & $70(36-84)$ & $33(13-73)$ & 7 \\
\hline Mozella et al & 2014 & $10(7 \backslash 3)$ & 10 & $71(59-80)$ & $35(26-45)$ & 3 \\
\hline Jensen et al & 2014 & $36(11 \mid 25)$ & 36 & $69(51-84)$ & $47(3-84)$ & 15 \\
\hline De Martino et al & 2015 & $18(12 \mid 6)$ & 18 & $73(55-84)$ & $80(71-105)$ & 13 \\
\hline Boureau et al & 2015 & $7(3 \mid 4)$ & 7 & $65(51-79)$ & $17(12-25)$ & 3 \\
\hline Brown et al & 2015 & $83(59 \mid 24)$ & 83 & $69(32-91)$ & $40(24-48)$ & 21 \\
\hline Bédard et al & 2015 & $21(12 \mid 9)$ & 21 & $75(58-91)$ & n.s. & 3 \\
\hline \multirow[t]{4}{*}{ Kamath et al } & 2015 & $63(36 \mid 27)$ & 66 & $67(41-83)$ & $70(60-106)$ & 26 \\
\hline & & & & & Clinical & \\
\hline & & & & & $68(60-106)$ & \\
\hline & & & & & Radiological & \\
\hline
\end{tabular}

Abbreviation: n.s., not specified.

2 were new infections. No clear information was provided for the remaining cases. In 13 studies (288 procedures), the number of septic revisions and the number of recurrent infections were clearly reported. Therefore, out of these 288 procedures, 202 were aseptic surgeries and the incidence of new infections was $0.99 \%$. Twenty-nine of these infections were surgically managed (either implant exchange or irrigation and debridement). In 14 of these septic procedures, the osteointegration of the related cone was evaluated and only two times a cone was found loose. An aseptic exchange was performed 13 times and a TM cone was found to be loose in 2 of the 11 procedures where this data was available. Signs of loosening of the TM cones (523), either radiological or from the surgical reports, were reported in 7 cases (1.33\%) (2 tibial cones and 5 femoral cones). Considering the 360 procedures with a mean follow-up of 42 months (range: 5-105) and a total of 432 cones implanted, the incidence of signs of loosening was $1.15 \%$ (5 TM cones) (-Table 4 ).

\section{Discussion}

The main finding of the current review is that the TM cones are an effective option to manage bone defects in complex primary and revision TKA. Signs of loosening were found just in the $1.33 \%$ of the $523 \mathrm{TM}$ cones implanted during 447 procedures. Interestingly, 5 of the 7 reported sings of loosening occurred in the femur. Limiting the analysis to the procedures with an available mean follow-up of 42 months (range: 5-105), the incidence of signs of loosening was $1.15 \%$. These data confirm the tantalum's capability to enhance tissue ingrowth and implant stability. Compared with other porous metal such as titanium or cobalt-chrome, tantalum has a much higher volume porosity, similarly to the cancellous bone (75-80\%). ${ }^{9,10,29,30}$ This feature makes tantalum an optimal substrate for bone ingrowth. ${ }^{8}$ Canine studies demonstrated fast bone ingrowth and revascularization of peri-implant bone with TM components., 6,9

The high coefficient of friction of tantalum provides an immediate mechanical stability. Therefore, impacting the TM cones in the metaphyseal bone offers immediate strong mechanical support that permits to control the rotational forces of the implant, therefore protecting the fixation of the implant, and supporting bone ingrowth from the adjacent host bone. Another feature of tantalum is its low modulus of elasticity that reduces the periprosthetic stress transfer to the host bone. ${ }^{9,10,29,30}$ This is an advantage considering the frequent need for high level of constraint frequently in revision TKA, as seen in this analysis, where 356 out of the 420 described implants were condylar constrained, rotating hinge, or pure hinge knees. Moreover, tantalum's immediate high stability and good stress transfer permits to use shorter stems compared with the ones required when structured allograft are used to manage bone loss. Indeed, the structured allografts require the use of long stems to protect their maturation process and longer stems, and this increases the possibility to have stress shielding problems. ${ }^{28,31}$ 
62 Efficacy of TM Cones to Address Metaphyseal Bone Loss Bonanzinga et al.

Table 3 Surgical reports

\begin{tabular}{|c|c|c|c|c|c|c|c|}
\hline Author & Implants & Constrain & $\begin{array}{l}\text { Bone defect } \\
\text { (AORI) }\end{array}$ & $\begin{array}{l}\text { Cones } \\
(\mathrm{T} \mid \mathrm{F})\end{array}$ & $\begin{array}{l}\text { Stem fixation } \\
(T \mid F)\end{array}$ & $\begin{array}{l}\text { Antibiotic } \\
\text { cement }\end{array}$ & $\begin{array}{l}\text { Stem } \\
\text { length (T|F) }\end{array}$ \\
\hline \multirow[t]{3}{*}{ Radnay and Scuderi } & 10 revision & n.s. & $2 \mathrm{~A}$ (n.s.) & $12(10 \mid 2)$ & Hybrid 4 & n.s. & T 75-200 \\
\hline & & & 2B (n.s.) & & Cemented 6 & & \\
\hline & & & 3 (n.s.) & & & & \\
\hline \multirow[t]{3}{*}{ Meneghini et al } & 15 revision & PS 6 & 2B (7) & $15(15 \mid 0)$ & Hybrid 3 & All & T 30-155 \\
\hline & & CC 2 & $3(8)$ & & Cemented 12 & & \\
\hline & & RH 7 & & & & & \\
\hline \multirow[t]{3}{*}{ Long and Scuderi } & 16 revision & CC 16 & $2 A(2)$ & $18(16 \mid 2)$ & Hybrid 12 & All & T 75-200 \\
\hline & & & $2 \mathrm{~B}(3)$ & & Cemented 4 & & \\
\hline & & & $3(13)$ & & & & \\
\hline \multirow[t]{3}{*}{ Howard et al } & 24 revision & PS 3 & 2B (n.s.) & $24(0 \mid 24)$ & Cemented 24 & n.s. & n.s. \\
\hline & & CC 11 & 3 (n.s.) & & & & \\
\hline & & RH 10 & & & & & \\
\hline \multirow[t]{3}{*}{ Lachiewicz et al } & 27 revision & PS 7 & 2B (4) & $33(24 \mid 9)$ & Hybrid $3 \mathrm{~T}+5 \mathrm{~F}$ & All & T 35-145 \\
\hline & & CC 17 & $3(29)$ & & Cemented 21T + 4F & & F 90-175 \\
\hline & & RH 3 & & & & & \\
\hline \multirow[t]{3}{*}{ Schmitz et al } & 38 revision & $\mathrm{RH} 13$ & $2 \mathrm{~A}\left(9^{*}\right)$ & $54(25 \mid 29)$ & Cemented 38 & All & n.s. \\
\hline & & HK 25 & $2 \mathrm{~B}\left(10^{*}\right)$ & & & & \\
\hline & & & $3\left(19^{*}\right)$ & & & & \\
\hline \multirow[t]{3}{*}{ Rao et al } & 26 revision & RH 26 & $2 \mathrm{~A}(16)$ & $29(25 \backslash 4)$ & Hybrid 26 & n.s. & $30-130$ \\
\hline & & & 2B (4) & & & & \\
\hline & & & $3(9)$ & & & & \\
\hline \multirow{3}{*}{$\begin{array}{l}\text { Villanueva- } \\
\text { Martínez et al }\end{array}$} & 21 revision & CC 11 & $2 A(3)$ & $29(11 \backslash 18)$ & Hybrid 12 & Not all & n.s. \\
\hline & & RH 10 & $2 B(6)$ & & Cemented 9 & & \\
\hline & & & $3(19)$ & & & & \\
\hline \multirow[t]{2}{*}{ Derome et al } & 29 revision & PS 11 & 2B (n.s.) & $33(17 \backslash 16)$ & Hybrid 29 & All & n.s. \\
\hline & & CC 18 & 3 (n.s.) & & & & \\
\hline \multirow[t]{3}{*}{ Mozella et al } & 10 revision & n.s. & $2 A(3)$ & $12(9 \mid 3)$ & Cemented 10 & All & n.s. \\
\hline & & & $2 B(5)$ & & & & \\
\hline & & & $3(4)$ & & & & \\
\hline \multirow[t]{3}{*}{ Jensen et al } & 36 revision & PS 6 & $2 \mathrm{~A} \mid 2 \mathrm{~B}(27)$ & $40(36 \mid 4)$ & Hybrid 36 & All & n.s. \\
\hline & & CC 14 & $3\left(9^{*}\right)$ & & & & \\
\hline & & RH 16 & & & & & \\
\hline \multirow[t]{2}{*}{ De Martino et al } & 18 revision & CC 6 & $2 B(6)$ & $25(12 \mid 13)$ & Hybrid 15 & All & T 100-155 \\
\hline & & RH 12 & $3(19)$ & & Cemented 3 & & F 100-155 \\
\hline \multirow[t]{2}{*}{ Boureau et al } & 7 revision & n.s. & $2 \mathrm{~B}(2)$ & $14(0 \mid 14)$ & n.s & n.s. & n.s. \\
\hline & & & $3(5)$ & & & & \\
\hline \multirow[t]{4}{*}{ Brown et al } & 4 primary & CR 1 & $1(13)$ & $94(76 \mid 18)$ & 83 cemented & n.s. & n.s. \\
\hline & 79 revision & PS 19 & $2 \mathrm{~A}(28)$ & & & & \\
\hline & & CC 52 & 2B (47) & & & & \\
\hline & & RH 11 & $3(6)$ & & & & \\
\hline \multirow[t]{3}{*}{ Bédard et al } & 21 revision & PS 3 & $2 B(6)$ & $25(17 \backslash 8)$ & 21 hybrid & n.s. & n.s. \\
\hline & & CC 17 & $3(19)$ & & & & \\
\hline & & $\mathrm{RH} 1$ & & & & & \\
\hline \multirow[t]{4}{*}{ Kamath et al } & 66 revision & CR 1 & $2 \mathrm{~A}(17)$ & $66(66 \mid 0)$ & 4 hybrid & All & T 30-155 \\
\hline & & PS 7 & $2 \mathrm{~B}(25)$ & & 62 cemented & & \\
\hline & & CC 33 & $3(24)$ & & & & \\
\hline & & RH 25 & & & & & \\
\hline
\end{tabular}

Abbreviations: AORI, Anderson Orthopaedic Research Institute; CC, condylar constrained; CR, cruciate retaining; HK, hinged knee; n.s., not specified; PS, posterior stabilized; $\mathrm{RH}$, rotating hinge. 
Table 4 Outcomes and complications

\begin{tabular}{|l|l|l|l|l|l|l|}
\hline Author & $\begin{array}{l}\text { Infections } \\
\text { (recurrent) }\end{array}$ & $\begin{array}{l}\text { Intraoperative } \\
\text { fractures } \\
\text { (fixed) [T|F] }\end{array}$ & $\begin{array}{l}\text { Septic } \\
\text { reoperations } \\
\text { (loose cones) }\end{array}$ & $\begin{array}{l}\text { Aseptic } \\
\text { revisions } \\
\text { (loose cones) }\end{array}$ & $\begin{array}{l}\text { Other } \\
\text { surgeries }\end{array}$ & $\begin{array}{l}\text { Signs of } \\
\text { loosening }\end{array}$ \\
\hline Radnay and Scuderi & $1(1)$ & 0 & $1(0)$ & 0 & 0 & 0 \\
\hline Meneghini et al & $2(2)$ & 0 & $2(0)$ & $2(0)$ & 0 & 0 \\
\hline Long and Scuderi & $2(2)$ & 0 & $2(0)$ & 0 & 0 & 0 \\
\hline Howard et al & $1(1)$ & 0 & 0 & 0 & 5 & 0 \\
\hline Lachiewicz et al & $1(1)$ & 0 & $1(1)$ & $1(1)$ & 2 & $2(2 \mathrm{~F})$ \\
\hline Schmitz et al & 0 & 0 & 0 & $2(1)$ & 0 & $1(1 \mathrm{~F})$ \\
\hline Rao et al & $2(2)$ & 0 & 1 (n.s.) & 0 & 0 & 0 \\
\hline Villanueva-Martínez et al & $2(2)$ & $8(3)[1 \mid 7]$ & $2(1)$ & 0 & 0 & $1(\mathrm{~F})$ \\
\hline Derome et al & $2(0)$ & $1(1[0 \mid 1])$ & $2(0)$ & $1(0)$ & 2 & 0 \\
\hline Mozella et al & 0 & 0 & 0 & 0 & 4 & 0 \\
\hline Jensen et al & $2(2)$ & 0 & $2(0)$ & $2(0)$ & 0 & 0 \\
\hline De Martino et al & $2(2)$ & 0 & $2(0)$ & 0 & 0 & 0 \\
\hline Boureau et al & 0 & 0 & 0 & 0 & 0 & 0 \\
\hline Brown et al & $9($ n.s.) & $1(1[0 \mid 1])$ & $9($ n.s.) & $2($ n.s.) & 8 & $1(\mathrm{~F})$ \\
\hline Bédard et al & 0 & $3(1)[2 \mid 1]$ & 0 & 0 & 0 & 0 \\
\hline Kamath et al & $7($ n.s.) & 0 & $5($ n.s.) & $3(1)$ & 9 & $2(\mathrm{~T})$ \\
\hline
\end{tabular}

Abbreviation: n.s., not specified.

Jafari et $\mathrm{al}^{32}$ have shown that, among the failed tantalum cups, $80 \%$ did so in the first 6 months, suggesting that a longtime survivorship should be expected with tantalum implants. This is another potential advantage with respect to the use of structured allograft that is associated with risk of collapse or resorption over the time. ${ }^{33}$ However, due to the recent introduction of the TM cones in the clinical practice, there is no available literature on the long-term survivorship of these devices. Beckmann et $\mathrm{al}^{5}$ have compared the revision rates of TM cones and structural allografts. They have collected the data of 476 knees with 551 allografts and 223 knees with 254 cones. According to their statistical analysis, they found a lower incidence of aseptic loosening in the TM studies.

Other potential advantages of TM cones include its modularity and the relatively safe and reproducible surgical technique. ${ }^{8}$ In this article, incidence of intraoperative fractures was $2.91 \%$ and the incidence of intraoperative fractures surgically fixed was $1.34 \%$. Interestingly, five of the seven fractures occurred in the femur. These data, together with higher incidence of cones loosening on the femoral side, suggest that particular attention is necessary when preparing the femoral metaphysis. Another possible clue may be the need for higher modularity on the femoral cones or maybe different shapes. Villanueva-Martínez et $\mathrm{al}^{20}$ reported about the need to reshape the cones 4 times out of 18 in the femoral side and 1 out of 11 implanted tibial cones.

The overall incidence of infection was quite low (7.38\%), further limiting the analysis to the aseptic procedures and the value was as low as $0.99 \%$. A previous review of the literature by De Martino and Sculco ${ }^{34}$ reported the incidence of infection to be $4.97 \%$ and the incidence of new infection between 1.16 and $1.21 \%$. On comparing the infection rates of studies reporting on TM cones and structured allografts, we observed that incidence of new infections was significantly lower in the TM studies, while the reinfection rate was similar. Possible reasons for this better performance of the TM cones could be related to the high volume of porosity of tantalum and to the shorter preparation time required for cones implantation compared with structured allografts.

The main potential drawback of the TM cones could be the difficulty of removing these augments in case of prosthetic joint infection. Unfortunately, the literature on this topic is quite limited.

Other metal options to address bone defects in knee revisions have been reported in the literature with variable results. Metal augments proved to be an efficient solution in contained defects with survival rate reported to be as high as $92 \%$ at long-term follow-up. ${ }^{35}$ However, Hockman et $\mathrm{al}^{36}$ noted that in those patients presenting with a type 3 bone defect ( $48 \%$ of the series), an additional large structural allograft was needed. Another option for severe metaphyseal defects are the titanium sleeves. Promising results have been published in the recent literature; however, the amount of studies available and the follow-up length are still limited. ${ }^{37}$

This study has some limitations. First, all the papers were case series as no controlled trials were available. Second, no assessment of methodological quality of the included studies was provided. Third, due to the lack of homogeneity among the included reports, not all the data were suitable for inclusion in the study analysis. For this reason, the calculation of the mean follow-up did not include one study ${ }^{28}$ with the second longer follow-up and the second bigger series. 
In conclusion, the TM cones proved to be an effective solution to address bone defects in complex primary and revision TKA at intermediate follow-up with low incidence of complications. The femoral side is more susceptible to intraoperative complications and aseptic loosening. Future studies with a higher level of evidence are needed to evaluate the long-term survivorship of these tantalum augments.

\section{Conflict of Interest}

Prof. Gehrke has received research support and consulting payments from Zimmer and Waldemar Link. Dr. Zahar has received consulting payments from Waldemar Link.

\section{References}

1 Hilgen V, Citak M, Vettorazzi E, et al. 10-year results following impaction bone grafting of major bone defects in 29 rotational and hinged knee revision arthroplasties: a follow-up of a previous report. Acta Orthop 2013;84(04):387-391

2 Morgan-Jones R, Oussedik SIS, Graichen H, Haddad FS. Zonal fixation in revision total knee arthroplasty. Bone Joint J 2015 ; 97-B(02):147-149

3 Engh GA, Ammeen DJ. Bone loss with revision total knee arthroplasty: defect classification and alternatives for reconstruction. Instr Course Lect 1999;48:167-175

4 Bush JL, Wilson JB, Vail TP. Management of bone loss in revision total knee arthroplasty. Clin Orthop Relat Res 2006;452(452):186-192

5 Beckmann NA, Mueller S, Gondan M, Jaeger S, Reiner T, Bitsch RG. Treatment of severe bone defects during revision total knee arthroplasty with structural allografts and porous metal conesa systematic review. J Arthroplasty 2015;30(02):249-253

6 LaBerge M, Bobyn JD, Rivard CH, Drouin G, Duval P. Study of soft tissue ingrowth into canine porous coated femoral implants designed for osteosarcomas management. J Biomed Mater Res 1990;24(07):959-971

7 Cohen R. A porous tantalum trabecular metal: basic science. Am J Orthop 2002;31(04):216-217

8 Levine B, Sporer S, Della Valle CJ, Jacobs JJ, Paprosky W. Porous tantalum in reconstructive surgery of the knee: a review. J Knee Surg 2007;20(03):185-194

9 Bobyn JD, Stackpool GJ, Hacking SA, Tanzer M, Krygier JJ. Characteristics of bone ingrowth and interface mechanics of a new porous tantalum biomaterial. J Bone Joint Surg Br 1999;81(05):907-914

10 Bobyn JD, Toh KK, Hacking SA, Tanzer M, Krygier JJ. Tissue response to porous tantalum acetabular cups: a canine model. J Arthroplasty 1999;14(03):347-354

11 Moher D, Cook DJ, Eastwood S, Olkin I, Rennie D, Stroup DF Improving the quality of reports of meta-analyses of randomised controlled trials: the QUOROM Statement. Onkologie 2000;23 (06):597-602

12 Wright JG, Swiontkowski MF, Heckman JD. Introducing levels of evidence to the journal. J Bone Joint Surg Am 2003;85-A(01):1-3

13 Radnay CS, Scuderi GR. Management of bone loss: augments, cones, offset stems. Clin Orthop Relat Res 2006;446(446):83-92

14 Meneghini RM, Lewallen DG, Hanssen AD. Use of porous tantalum metaphyseal cones for severe tibial bone loss during revision total knee replacement. J Bone Joint Surg Am 2008;90(01):78-84

15 Long WJ, Scuderi GR. Porous tantalum cones for large metaphyseal tibial defects in revision total knee arthroplasty: a minimum 2-year follow-up. J Arthroplasty 2009;24(07):1086-1092

16 Howard JL, Kudera J, Lewallen DG, Hanssen AD. Early results of the use of tantalum femoral cones for revision total knee arthroplasty. J Bone Joint Surg Am 2011;93(05):478-484
17 Lachiewicz PF, Bolognesi MP, Henderson RA, Soileau ES, Vail TP. Can tantalum cones provide fixation in complex revision knee arthroplasty? Clin Orthop Relat Res 2012;470(01):199-204

18 Schmitz H-CR, Klauser W, Citak M, Al-Khateeb H, Gehrke T, Kendoff D. Three-year follow up utilizing tantal cones in revision total knee arthroplasty. J Arthroplasty 2013;28(09):1556-1560

19 Rao BM, Kamal TT, Vafaye J, Moss M. Tantalum cones for major osteolysis in revision knee replacement. Bone Joint J 2013;95-B (08):1069-1074

20 Villanueva-Martínez M, De la Torre-Escudero B, Rojo-Manaute JM, Ríos-Luna A, Chana-Rodriguez F. Tantalum cones in revision total knee arthroplasty. A promising short-term result with 29 cones in 21 patients. J Arthroplasty 2013;28(06):988-993

21 Derome P, Sternheim A, Backstein D, Malo M. Treatment of large bone defects with trabecular metal cones in revision total knee arthroplasty: short term clinical and radiographic outcomes. J Arthroplasty 2014;29(01):122-126

22 Mozella Ade P, Olivero RR, Alexandre H, Cobra AB. Use of a trabecular metal cone made of tantalum, to treat bone defects during revision knee arthroplasty. Rev Bras Ortop 2014;49(03):245-251

23 Jensen CL, Winther N, Schrøder HM, Petersen MM. Outcome of revision total knee arthroplasty with the use of trabecular metal cone for reconstruction of severe bone loss at the proximal tibia. Knee 2014;21(06):1233-1237

24 De Martino I, De Santis V, Sculco PK, D’Apolito R, Assini JB, Gasparini G. Tantalum cones provide durable mid-term fixation in revision TKA. Clin Orthop Relat Res 2015;473(10):3176-3182

25 Boureau F, Putman S, Arnould A, Dereudre G, Migaud H, Pasquier G. Tantalum cones and bone defects in revision total knee arthroplasty. Orthop Traumatol Surg Res 2015;101(02):251-255

26 Brown NM, Bell JA, Jung EK, Sporer SM, Paprosky WG, Levine BR. The use of trabecular metal cones in complex primary and revision total knee arthroplasty. J Arthroplasty 2015;30(9, Suppl):90-93

27 Bédard M, Cabrejo-Jones K, Angers M, Pelletier-Roy R, Pelet S. The effect of porous tantalum cones on mechanical alignment and canal-fill ratio in revision total knee arthroplasty performed with uncemented stems. J Arthroplasty 2015;30(11):1995-1998

28 Kamath AF, Lewallen DG, Hanssen AD. Porous tantalum metaphyseal cones for severe tibial bone loss in revision knee arthroplasty: a five to nine-year follow-up. J Bone Joint Surg Am 2015;97(03):216-223

29 Bobyn JD, Hacking SA, Krygier JJ, Harvey EJ, Little DG, Tanzer M. Zoledronic acid causes enhancement of bone growth into porous implants. J Bone Joint Surg Br 2005;87(03):416-420

30 Hacking SA, Bobyn JD, Toh K, Tanzer M, Krygier JJ. Fibrous tissue ingrowth and attachment to porous tantalum. J Biomed Mater Res 2000;52(04):631-638

31 Brooks PJ, Walker PS, Scott RD. Tibial component fixation in deficient tibial bone stock. Clin Orthop Relat Res 1984;(184):302-308

32 Jafari SM, Bender B, Coyle C, Parvizi J, Sharkey PF, Hozack WJ. Do tantalum and titanium cups show similar results in revision hip arthroplasty? Clin Orthop Relat Res 2010;468(02):459-465

33 Dennis DA. The structural allograft composite in revision total knee arthroplasty. J Arthroplasty 2002;17(04, Suppl 1):90-93

34 De Martino I, Sculco PK. In response to "treatment of severe bone defects during revision total knee arthroplasty with structural allografts and porous metal cones-a systematic review". J Arthroplasty 2015;30(07):1287-1289

35 Patel JV, Masonis JL, Guerin J, Bourne RB, Rorabeck CH. The fate of augments to treat type-2 bone defects in revision knee arthroplasty. J Bone Joint Surg Br 2004;86(02):195-199

36 Hockman DE, Ammeen D, Engh GA. Augments and allografts in revision total knee arthroplasty: usage and outcome using one modular revision prosthesis. J Arthroplasty 2005;20(01):35-41

37 Sculco PK, Abdel MP, Hanssen AD, Lewallen DG. The management of bone loss in revision total knee arthroplasty: rebuild, reinforce, and augment. Bone Joint J 2016;98-B(1, Suppl A):120-124 